\title{
Safe tree felling using expansion agent
}

CrossMark

\author{
Chyon Hae Kim ${ }^{1 *}$, Hiroaki Abe ${ }^{2}$, Akio Numakura' ${ }^{1}$ Jyunpei Koyama ${ }^{3}$ and Yukio Takahashi ${ }^{4}$
}

\begin{abstract}
We discuss about safe tree felling methods. In previous work, tree felling robots that were equipped with cutting instruments have been investigated in order to keep workers' safety. However, these robots may take damage when trees fall down against them. We propose a tree felling framework that maintains the workers and robots both in safe. In the proposed framework, a robot inserts a slow-acting expansion agent at the trunk of a tree. While the agent is expanding, the workers and robots escape from the tree. Also, we propose two drilling methods that are able to realize the proposed framework. In the experiments, conventional drilling methods that have been used for rocks did not divide logs. On the other hand, the proposed methods realized the divisions without any crack in the product side of them. The proposed methods were effective against standing trees too.
\end{abstract}

Keywords: Tree felling, Expansion agent, Automation

\section{Background}

25 million (ha) $(66 \%)$ of Japanese ground is covered by forest. The total volume of tree trunks (about 5 billion $\left[\mathrm{m}^{3}\right]$ ) is increasing year by year. The background of the increasing is the low self-sufficiency of wood in Japan. Compared with 1966, the total volume has been increased to 5.5 times in 2012. Self-sufficiency of wood has been decreased from 71.4 to $27.9 \%$.

From these facts, Forestry Agency of Japan is targeting increasing the self-sufficiency to 50\% until 2020 [6]. However, the number of forestry workers has been decreased from 0.26 million (1965) to 0.10 million (1990) [7]. One of the reasons of the decreasing is the high accident rate of forestry industry. In forestry, 1700 industrial accidents occur in a year. Half of them are occurring while tree felling tasks. According to 1000 rate, ${ }^{1}$ forestry is 28.7 , which is quite higher than manufacturing (2.8) and construction $(5.0)[8,9]$.

One of the reasons why the number of accidents is not decreasing is that the falling direction of a tree is unpredictable. Even when typical Japanese workers use a sophisticated tree cutting method, ukekuchi-oikuchi cut, the direction is not sufficiently predictable. Also, we have

\footnotetext{
*Correspondence: tenkai@iwate-u.ac.jp

${ }^{1}$ Iwate University, 203 Room, 4 Bldg. East, 4-3-5 Ueda, Morioka, Iwate, Japan

Full list of author information is available at the end of the article
}

no way to measure the center of mass of a tree before falling down in current technology. For example, we can not select a good wave frequency for non-destructive inspection that uses ultrasonic sound wave or some other waves against trees. Tree does not let high frequency wave pass it. If we use a low frequency wave, non-destructive inspection does not assure its precision.

From the above, the establishment of safe tree felling methods is an urgent need. In order to fill it, forestry machines have been developed. Feller buncher and harvester are popular forestry machines. However, these machines are not in use around steep or soft ground, because of their large weights. Also, dense forest gets rid of the use of them, because of their sizes. Currently, a large number of workers are using chainsaw in order to divide a tree, although it has much possibility of accidents.

Smaller sized robots may fit the conditions like steep ground, soft ground, or dense forest. Sugano et al. developed a pruning robot that climes a tree using two robot arms [12]. Ishigure et al. developed a pruning robot that cuts the branches of a tree using a chainsaw. This robot is able to climb a tree using 4 wheels [5]. Meaclem et al. investigated a biped mechanism of a felling machine that climbs between trees using two legs like a monkey [11]. Kolb et al. proposed a tree trunk detection system for a

\footnotetext{
1 The number of injured workers in a year among 1000 workers.
} 
semi-autonomous tree felling robot [10]. Gui et al. developed an anti falling mechanism for tree pruning robots [3]. Especially, Sugano et al. developed a remote control robot that is equipped with chainsaw at the end effector of its robot arm [2]. However, a falling tree may crash these robots, because they must be close to the tree in order to cut it even when the tree falls down. Inserting remotely reacting materials in a tree is a new idea to keep the safety of robots.

In this paper, we propose a tree felling framework in that a robot is able to escape safely before a tree falls. In the proposed framework, a robot inserts a slow-acting expansion agent at the trunk of a tree. While the agent is expanding, the workers and robots are able to escape from the tree safely. We propose two drilling methods that realize the proposed framework.

In "Materials, methods and proposition" section, the propositions are described. In "Experiment" section, the effectiveness of the proposed drilling methods and conventional methods were examined through fracture experiments. In "Discussion" section, discussion is presented based on the results. In "Conclusion" section, this work is summarized.

\section{Materials, methods and proposition}

We proposed a framework in that a robot inserts a slowacting expansion agent at the trunk of a tree and escapes from the tree before the reaction starts (Fig. 1). This method allows both a worker and a robot to be completely safe when a tree falls down.

In order to establish safe tree felling using expansion agent, we must consider the followings:

1. Type of expansion agent.

2. Drilling method.

\section{Type of expansion agent}

In forest, we must use an expansion agent that does not damage the surrounding environment (1). Also, the

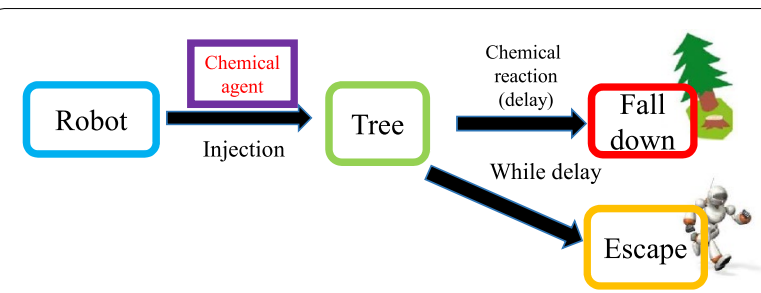

Fig. 1 Proposed framework. In the proposed framework, robot inserts chemical expansion agent to a tree. The robot is able to escape from the tree, while the agent is reacting. Thus, both human and robot are safe when the tree falls down expansion agent must make sufficient stress in the trunk in order to cut the fibers (2). Moreover, the expansion agent should be safe in handling (3).

If we use gunpowder [4], it is able to divide the trunk. However, the left residual material makes pollution around the tree. Also, handling it inside forest is dangerous. On the other hand, making the stress using some devices such as an air bag is not in use, these devices do not make sufficient stress. We need to select the expansion agent that is able to make more pressure than the strength of wood (Table 1) at least.

Non-explosive demolition agent (NDA) is a candidate of the expansion agent. NDA is frequently used for breaking up rocks inside forest. The chief component of NDA is calcium oxide that makes expansion pressure in hydration reaction with water. Commercially available NDA is able to make about $80\left(\mathrm{~N} / \mathrm{mm}^{2}\right)$, which is more than the strength of wood. Calcium hydrate, which is left after the reaction of calcium oxide and water, does not make damage forest. Calcium hydrate is frequently used for the sterilization of forest. NDA is safe in handling. It does not any license in Japan, because of its safety.

In this paper, we use NDA for validating the proposed framework. For NDA, we used Power Blister of Taiheiyo Material Co. Ltd. in the experiments. This NDA makes solid cap quickly around a hole in that it is inserted.

In previous work, NDA has not been used for dividing a tree. The target was restricted to rock that is isotropic material.

\section{Drilling method}

In order to fell a tree using NDA, the way of drilling is important.

In case of isotropic material, NDA is inserted in the holes that are opened in a rock according to the following equation like Fig. 2. We prepared two methods that apply conventional drilling methods to trees like Fig. 3. Later, we validate these methods in order to obtain base lines in the experiments.

$$
L=K d
$$

where, $L$ is the distance between the holes, $K$ is breakup coefficient which is decided by the class of the rock, $d$ is the diameter of the holes.

Table 1 Strength of $\operatorname{wood}\left(\mathrm{N} / \mathrm{mm}^{2}\right)$ [1]

\begin{tabular}{lllll}
\hline Wood & Compressive & Tensile & Bending & Shear \\
\hline Larch & 23.4 & 18.0 & 29.4 & 2.1 \\
Fir & 27.0 & 20.4 & 34.2 & 1.8 \\
Cedar & 21.6 & 16.2 & 27.0 & 1.8 \\
\hline
\end{tabular}




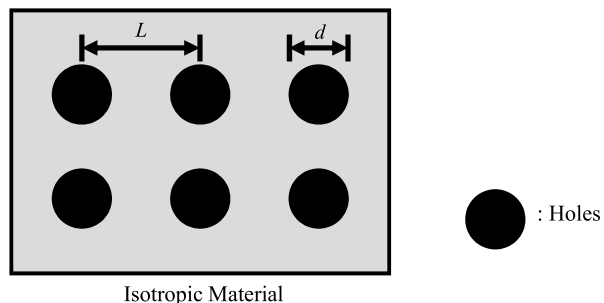

Fig. 2 Drilling of isotropic material. In conventional drilling against rocks, the holes have been opened with a uniform distance

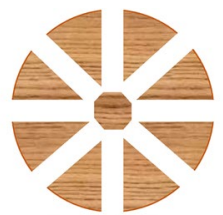

(1) Conventional drilling method A

(2) Conventional drilling method B

Fig. 3 Conventional drilling methods. In conventional drilling method $A$, holes are opened radially. In conventional drilling method $B$, holes are opened straightly

As in Table 1, the strength of the material is different according to the directions. Also, tree is composed of fibers that extend in the longitudinal direction. Therefore, the best drilling method might be not symmetrical. When holes are placed radially [Fig. 4(1)] like the previous method, the pressure from the holes make compression force in the logs. This is not effective to tear the fibers. When holes are placed straightly [Fig. 4(2)], the pressure from the two end-holes does not compress the fibers of the outside. This pressure effectively makes cracks. But, almost all pressure inside the log works as compression force in this drilling too, if all of the holes are placed at the same height. We might need to differentiate the heights of the holes in order to tear the fibers effectively.

The requirements of the drilling method is as follows:

1. Is able to fell a tree.

2. Easiness of automation.

3. Quality of wood.

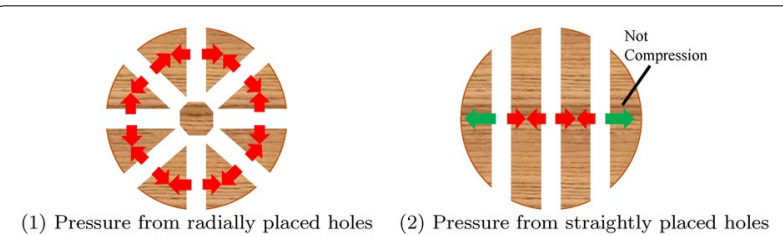

Fig. 4 Pressure. In conventional methods, almost all pressure that affects the fibers of a tree is compressive force. This might be the reason why the fibers did not take a large damage in the following experimental results
If tree does not fall down after the reaction, this framework is useless. We need to fill the first requirement at first. The second requirement is related to the efficiency. If automation of this method is difficult, workers need to insert the expansion agent by themselves. This cost much time and employment fee. The third requirement is the quality of wood after felling. If product wood takes damage, the wood reduces its value. We need to avoid a large crack that extends to the longitudinal direction of a tree, because this type of crack is easily occur along the fibers of tree and it damages the production part of a tree.

On the basis of the requirements, we propose two drilling methods as in Figs. 5 and 6. In both proposed methods, holes are placed close in horizontal direction, in order to stop the extension of a crack in longitudinal direction.

In proposed drilling method A, two holes are drilled vertically with distance $d_{1}$. For the lower hole, a cut that reaches to the hole is made using a chainsaw. Above the upper hole, another cut is made with a distance $d_{2}$ from the upper hole where $d_{2}$ is larger than radius $d / 2$ of the hole. This drilling method divides the trunk by chaining the two holes by the pressure of expansion agent. This method utilizes the specification of a tree where vertical crack is easily made by weak pressure. The fibers in the trunk of a tree are directing to the longitudinal direction of a tree. Cracks are easily made along the fibers. The distance between the upper hole and the cut above the hole is required in order to avoid the crack in production parts (above the cut). If this cut does not exist, the pressure around the upper hole affects all surrounding directions. This cut stops the pressure to the upward. The robot that performs this method must use two mechanical tools (drill and chainsaw).

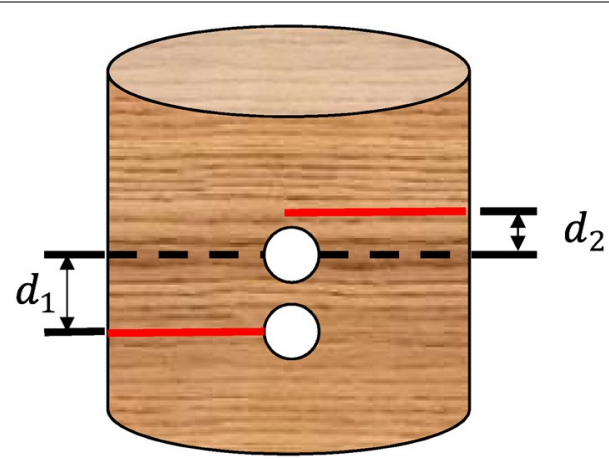

Fig. 5 Proposed drilling method A. In proposed drilling method A, two holes are opened in the longitudinal direction of the tree. A cut is made from the surface of the tree to the lower hole. The second cut is made above the upper hole. After the reaction of expansion agent, two holes are connected by a crack. The upper cutstops the crack in order to keep the product part without damage 


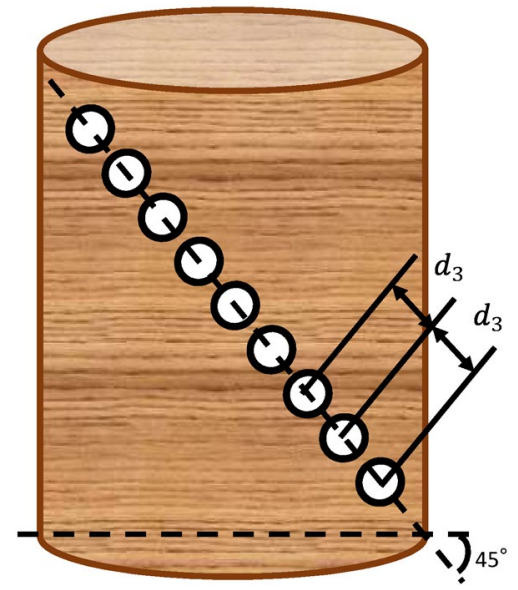

Fig. 6 Proposed drilling method B. In proposed drilling method B, a line of holes is made at $45\left(^{\circ}\right)$ against the longitudinal direction of the tree so that the angled holes affect sharing force to the fibers of the tree

In proposed drilling method $\mathrm{B}$, holes are lined with 45 $\left(^{\circ}\right)$ with a constant distance. As we mentioned the above, trees have fibers in the longitudinal directions. Making shearing stress around the fibers is reasonable to divide a tree. The $45\left(^{\circ}\right)$ line makes the sharing stress. If the holes are lined with $0\left(^{\circ}\right)$ (horizontally), the pressure from two beside holes makes compressive force around the fibers. This is not effective to break the fibers. Thus, the previous method in Fig. 2 is not effective to a tree as we examine later. The robot that performs this method requires only drill. Thus, the implementation for a robot is easier than proposed drilling method A.

Addition to the proposed drilling methods, we prepared some drilling methods like Fig. 7 in order to compare them with proposed drilling methods. These

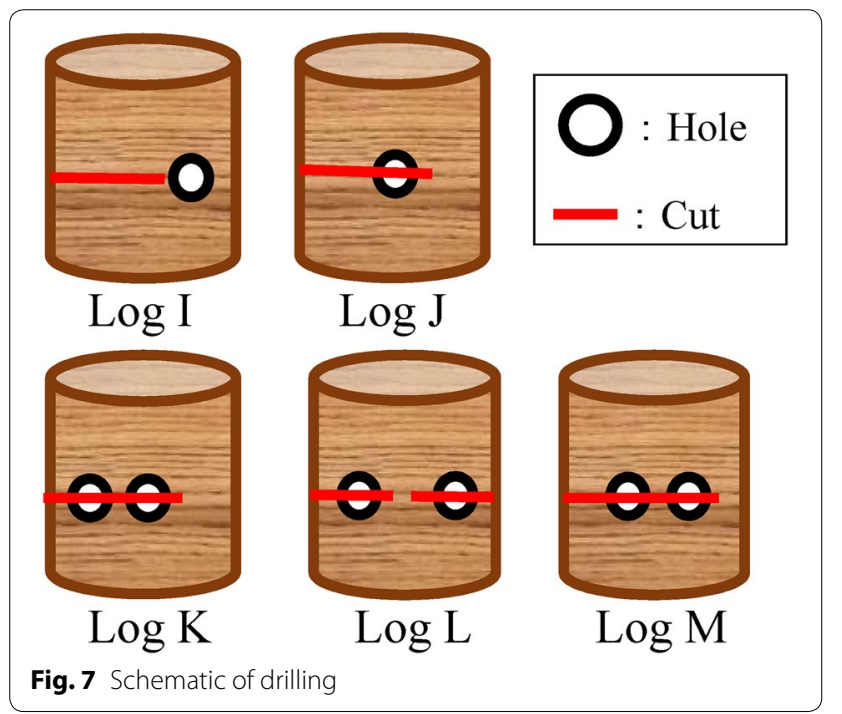

methods are also our original and not included in the previous drilling methods that have been applied to rocks.

\section{Experiment Settings}

In the experiment, the proposed method and previous method were compared using cedar logs that have about 400 (mm) length, about 180-200 (mm) diameter. The procedure of the experiment is as follows:

1. Drilling the log.

2. Putting NDA in water for $4 \mathrm{~min}$.

3. Filling the holes by NDA.

4. Confirming the result $14 \mathrm{~h}$ later.

We conducted 6 experiments. In Experiment 1, we made holes using Conventional drilling method A. In Experiment 2, we made holes using Conventional drilling method B. These two experiments were done in order to confirm the effectiveness of conventional drilling methods. The results of them show the base lines of the proposed methods.

In Experiment 3, we made holes as in Fig. 7. In this experiment, we confirmed the effectiveness of the NDA when the holes are opened holizontally with some cuts. If holizontal cuts were enlarged by the NDA, these methods were good solutions.

In Experiment 4, we made holes using the proposed drilling method A. In Experiment 5, we made holes using the proposed drilling method $\mathrm{B}$. These two experiments were done in order to confirm the effectiveness of the proposed methods.

In Experiment 6, we examined the both proposed drilling methods in forest in order to confirm their applicability on the field. This experiment was done under the temperature of $9.0-13.7\left({ }^{\circ} \mathrm{C}\right)$ in a forest of Kamaishi City in Iwate Prefecture of Japan. The altitude was around 10 (m). The slope gradient was $0-25\left(^{\circ}\right)$. For method A and $\mathrm{B}$, we used cedar trees with diameters of 277 and 234 $(\mathrm{mm})$. Before the experiment, the trees around the targeted tree were cut, in order to assure the safety of the experiment.

All of the holes were filled by NDA.

Table 2 shows the detailed drilling patterns of the logs A-G that were used in Experiment 1. The durations of the holes were set evenly around the circumference of the trunk. The holes were opened in the order of front, back, front, back, etc. Especially for Log G, we covered the surface of inside the holes using vinyl sheets in order to prevent the water in NDA from absorption. Figure 8 shows the drilled logs. 
In Experiment 2, we made Log $\mathrm{H}$ that had 3 holes with $30(\mathrm{~mm})$ diameter using previous method $\mathrm{B}$ as in Fig. 8(4). The first hole was made at the center of the log. The lest of it was made at $60(\mathrm{~mm})$ left/right from the center.

In Experiment 3, we made $30(\mathrm{~mm})$ diameter holes after making the cuts using a chainsaw. Table 3 shows the parameters. Figure 7 shows the schematic of the drilling.

In Experiment 4, parameters $d_{1}$ and $d_{2}$ were set at 80 and $20(\mathrm{~mm})$ respectively for $\log \mathrm{N}$.

In Experiment 5, parameters $d_{3}$ was set at $50(\mathrm{~mm})$ for Log O.

In Experiment 6, we used the same parameters as Experiment 4 and 5 for two standing trees, and used $d_{3}=35$ for a tree and connected half holes by drill while grabbing the production part of the tree using a harvester in order to conduct the experiment in safe.

\section{Results}

Figure 9 shows $\log \mathrm{C}, \mathrm{D}$, and $\mathrm{F}$ after the reaction of NDA in Experiment $1 . \log C$ and D did not change their appearance. Log F got a small crack. Figure 10 shows the cross-section surfaces of $\log E$ and $G$. The volume of NDA increased regardless the existence of vinyl sheets. Conventional drilling method A could not divide the logs.

Figure 11 shows the outer appearance and cross-section surface of $\log \mathrm{H}$ after the reaction of the expansion agent in Experiment 2. By straightly made holes, a larger crack than that of Log F appeared. However, the crack did not connect the holes.

Figure 12 shows the results of Experiment 3. Log I was not divided, although clacks appeared in the longitudinal
Table 3 Drilling parameter (Experiment 3)

\begin{tabular}{|c|c|c|}
\hline & Cut & Position of holes \\
\hline $\log \mid$ & About 2/3 of the log & $20(\mathrm{~mm})$ from the cut \\
\hline Log $J$ & $10(\mathrm{~mm})$ beyond the hole & Center \\
\hline $\log K$ & $10(\mathrm{~mm})$ beyond the hole & $\begin{array}{l}\text { Center and } 50(\mathrm{~mm}) \text { left from the } \\
\text { first hole }\end{array}$ \\
\hline Log L & $10(\mathrm{~mm})$ beyond the hole & $50(\mathrm{~mm})$ from the edges \\
\hline $\log M$ & $10(\mathrm{~mm})$ beyond the hole & $\begin{array}{l}60 \text { and } 110(\mathrm{~mm}) \text { from the right } \\
\text { edge }\end{array}$ \\
\hline
\end{tabular}

direction. The expansion agent in Log J and $\mathrm{K}$ enlarged the cuts of the logs, especially Log K got larger affection. Log $\mathrm{L}$ got the clacks from the holes in the longitudinal direction. In Log M, the cut was enlarged and the log was split in the longitudinal direction. However, all of the logs did not divided in horizontal direction. Also, the upper parts of the logs, which will be used, took damage.

Figure 13 shows the results of Experiment 4. The proposed method A was able to divide Log $\mathrm{N}$ horizontally through creating the crack between the holes.

Figure 14 shows the results of Experiment 5. The proposed method B was able to divide Log O horizontally through creating the crack between the holes.

Figures 15, 16, and 17 show the experimental results in forest. Both proposed drilling methods were effective against standing trees. Also the product parts of the felled trees [Fig. 17(1), (2)] did not have cracks. Figure 17(3) is the result of the test for the safety while drilling. In this experiment, the thickness of the tree was cut in to less than $1 / 5$ of the other two trees. Even in this condition, the tree could stand without falling.

Table 2 Drilling parameters (Experiment 1)

\begin{tabular}{lccccccrr}
\hline Log & A & B & C & D & E & F & G (vinyled) & H \\
\hline$d(\mathrm{~mm})$ & 10 & 10 & 10 & 25 & 25 & 40 & 25 & 30 \\
Number of holes & 6 & 8 & 10 & 10 & 8 & 8 & 10 & 8 \\
\hline
\end{tabular}

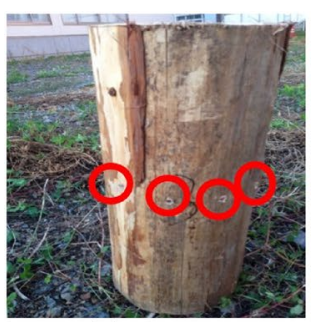

(1) $\log \mathrm{C}$

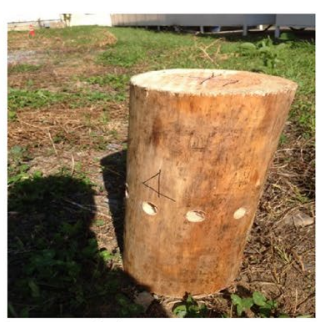

(2) $\log D$

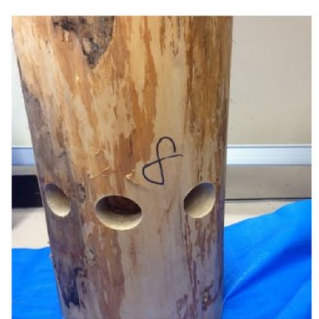

(3) $\log \mathrm{F}$

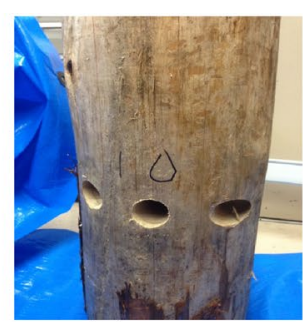

(4) $\log \mathrm{H}$

Fig. 8 Logs drilled by conventional method A (1-3) and B (4) 


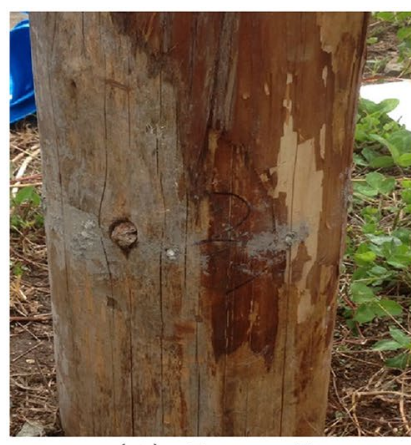

(1) $\log C$

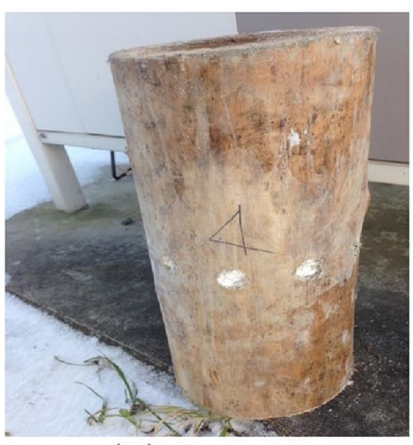

(2) $\log \mathrm{D}$

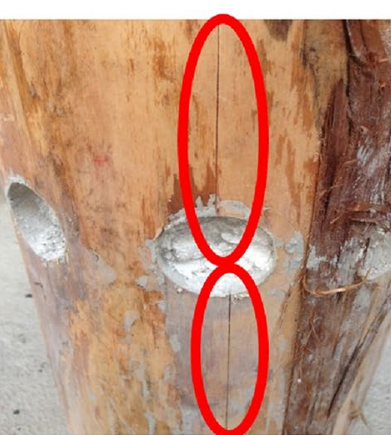

(3) $\log F$

Fig. 9 Results of conventional drilling method A. Conventional drilling method A could not divide the logs. But, when the holes were large (3), crack was appeared on the surface of the log

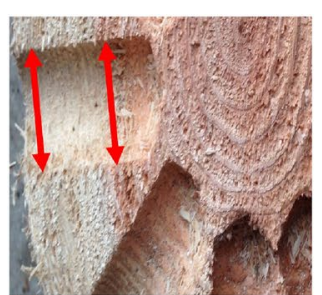

(1) Before experiment

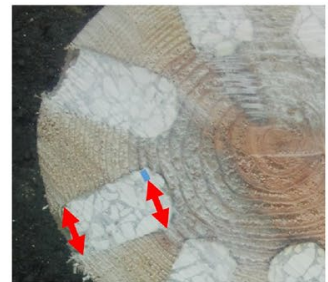

(2) After experiment (Log E)

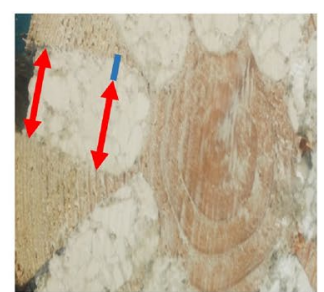

(3) After experiment (Log G (vinyled))

Fig. 10 Cross-section surfaces. In drilling method A, NDA expanded the holes by its pressure

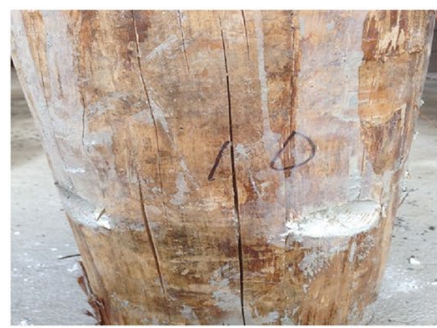

(1) Surface after reaction

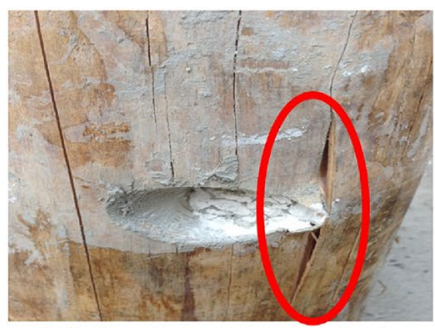

(2) Surface around hole

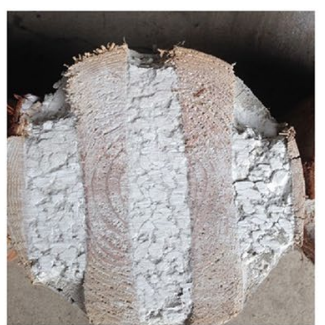

(3) Cross-section surface

Fig. 11 Result of Log H. In drilling method B, larger cracks than those of drilling method A appeared around holes. However, the logs were not divided

\section{Discussion}

\section{Requirements}

The two proposed methods might be effective to fell trees, because they could divide even the logs that take no pressure from the above. In actual trees, the tearing of fibers easily occurs by their self-pressure.

Proposed method B is quite easy to be automated, because it requires only drills. Automating proposed method A might be more difficult than that of B, because proposed method A requires two types of mechanical tools. But, we can not get rid of the use of proposed method A completely, because proposed drilling method A requires less amount of NDA than proposed method B.

The both proposed methods effectively kept the quality of woods. In the experiments, any crack occurred on the surface of the product parts.

\section{Diameter of holes}

The effective diameter of holes is larger than $25(\mathrm{~mm})$, because the holes with $25(\mathrm{~mm})$ did not extend any crack 


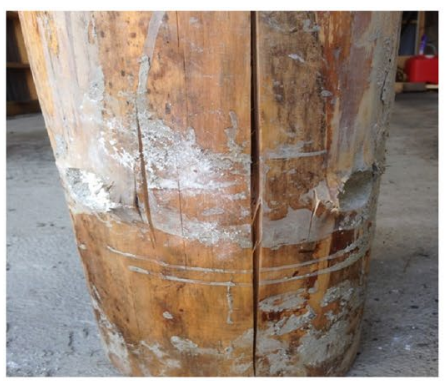

(1) $\log I$

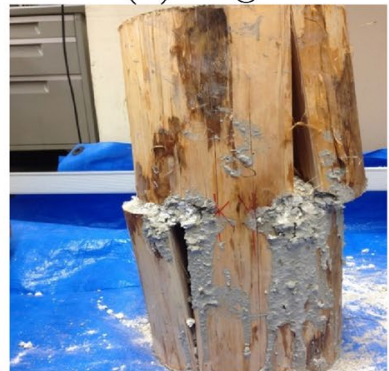

(1) $\log \mathrm{L}$

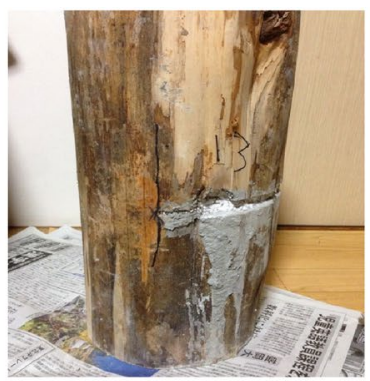

(2) $\log J$

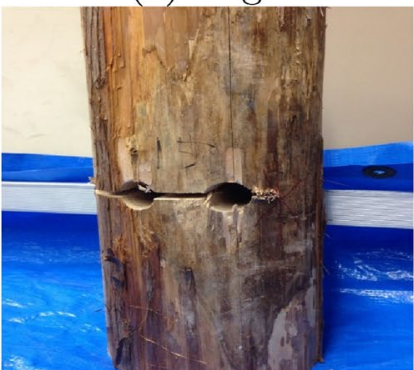

(2) Log M (before)

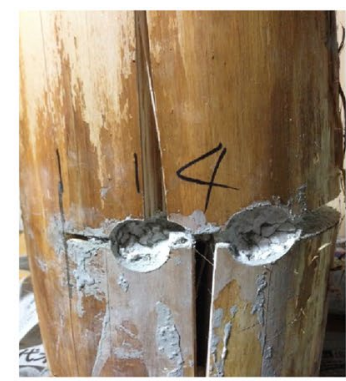

(3) $\log \mathrm{K}$

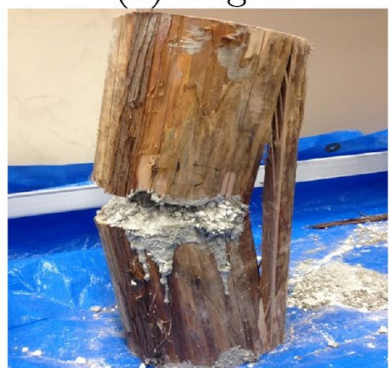

(3) $\log M$

Fig. 12 Results of Experiment 3. A variety of drilling methods were tested. However, NDA made cracks in the product part of the trees in these methods

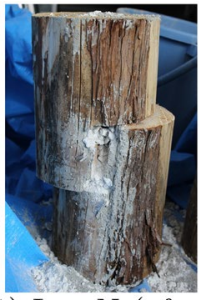

(1) Log N (after)

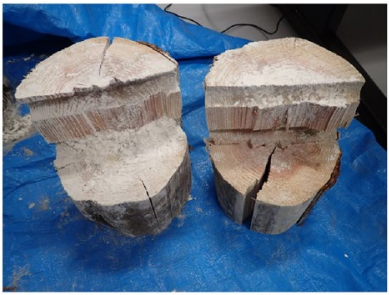

(2) $\log N$ (cross section surface)
Fig. 13 Result of Experiment 4. Proposed drilling method A could divide the log without any crack in the product part

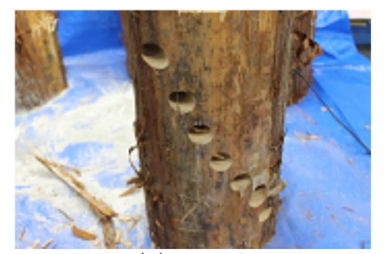

(1) $\log \mathrm{O}$

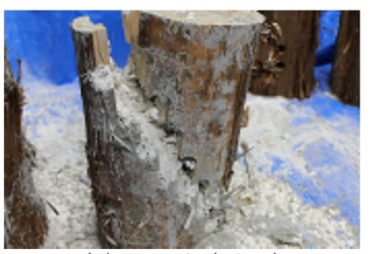

(2) $\log \mathrm{O}$ (after)
Fig. 14 Result of Experiment 5. Proposed drilling method B could also divide the log without any crack in the product part in Experiment 1. This reason might be the shortage of the volume of the expansion agent. From the cross section surface of Log $\mathrm{E}$ and $\mathrm{G}$, we can confirm the effectiveness directly.

\section{Additional cuts}

We can make tearing force by making additional cuts after drilling like Experiment 3. In this experiment, the pressure around the holes works only up and down. However, controlling the tearing force so that it affects only horizontal direction was difficult, because of the fibers that are placed in longitudinal direction. As a result, logs were torn along with the fibers. Proposed method A is effectively using the characteristic of the fibers. The crack in longitudinal direction is included in the division surface of resulting two piece of woods.

\section{Reaction time}

In the proposed method, we can control the reaction duration of the expansion agent. The reaction time of calcium oxide is quite rapid. In NDA, it is supressed by additional materials. Thus, we can easily control the duration by changing the amount of the additional materials.

The workers of Kamaishi Forest Ownership Association want to use it at night. If they set the expansion agent and alarms, they can sleep in a lodge while the reaction occurs. After the reaction, they can take the trees on the ground at the tomorrow morning.

\section{Automation}

Although the proposed methods allow a worker to fell a tree safer than previous methods, we need to automate the drilling method and insertion method in order to 


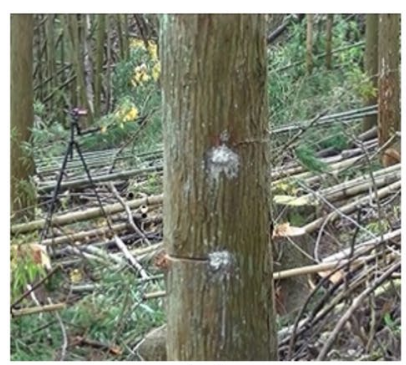

(1)

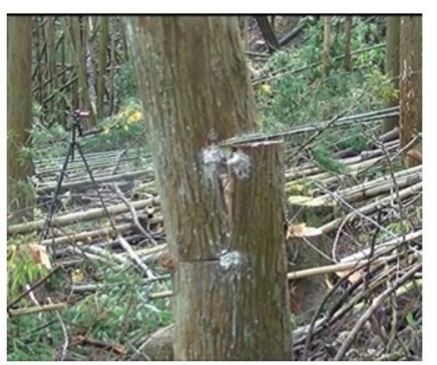

(2)

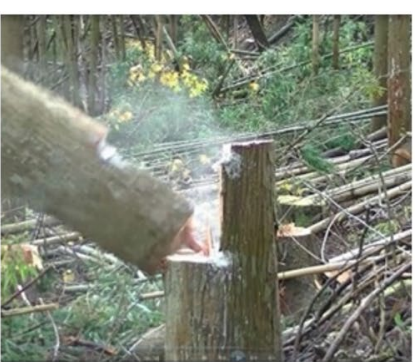

(3)

Fig. 15 Result of Experiment 6 (method A)

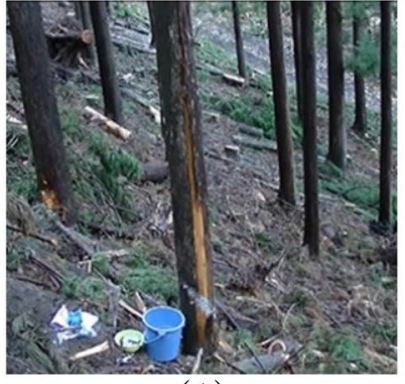

(1)

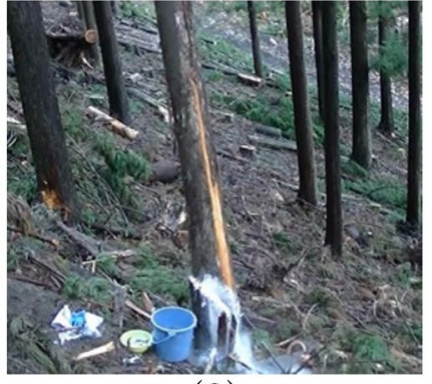

(2)

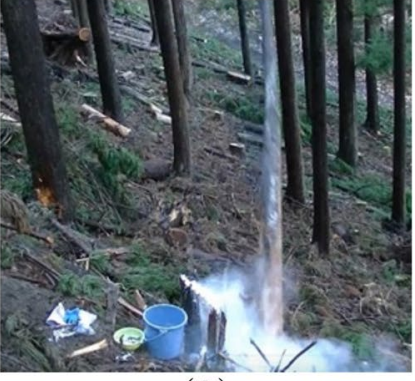

(3)

Fig. 16 Result of Experiment 6 (method B)

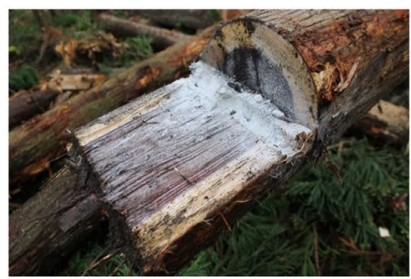

(1)

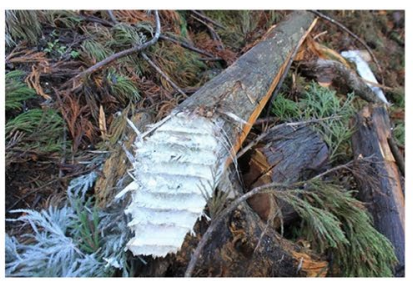

(2)

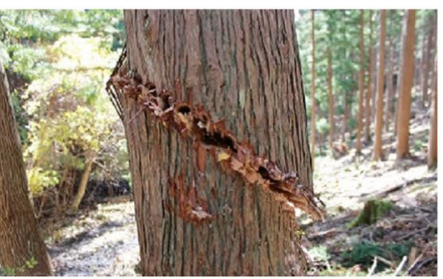

(3)

Fig. 17 Result of Experiment 6 [product part (1) (2) and additional test (3)]

make sale product, because manual drilling and insertion cost a large time (currently about $20 \mathrm{~min}$ ). If we consider the automation of drilling method, proposed drilling method B might be better than proposed drilling method A, because it requires only a type of cutting tool and might be realized by cheaper price. But, if we consider the amount of required expansion agent, drilling method A might be better. For the automation of the insertion, we can use a lapped expansion agent. Currently, the reason why insertion process costs much time is that expansion agent is half liquid. If we lap it, we can handle it like a solid. After the development of these automation techniques, the time to set expansion agent might be going to be $1 \mathrm{~min}$ or so.

\section{Drawbacks}

We summarize the drawbacks of the proposed methods. Firstry, the proposed methods require NDA addition to mechanical system for cutting a tree. Even if the finantial cost of NDA is small, it is not zero. Secondly, there is no evidence that the proposed methods are able to control falling direction of a tree. We need additional experiments and improvements in order to assure controllability. Thirdly, we need additional devices that alart a person who comes close to a tree that took NDA in order to assure the safety of people. Especially when using NDA while workers are sleeping, exclusion zone of the forest must be set. To sign the exclusion zone, we need additional devise. 


\section{Conclusion}

We proposed tree felling framework that take into account the safety of workers and robots. In the framework, we proposed two drilling methods too. The proposed methods effectively divided logs through the reaction of expansion agent with time delay. Thus, all of the workers and robots are able to escape from the tree before it falls down. From the experiments, the radius of the holes should be more than $25(\mathrm{~mm})$. The directions of the holes should be straight. The heights of the holes should be differentiated. In the proposed drilling methods, all of these features are took into account.

\section{Authors' contributions}

CHK proposed the consept, analyzed and interpreted data, and wrote the manuscript. HA, AN, and JK acquired data. All authors read and approved the final manuscript.

\section{Author details}

${ }^{1}$ I wate University, 203 Room, 4 Bldg. East, 4-3-5 Ueda, Morioka, Iwate, Japan. ${ }^{2}$ Wiseman Co. Ltd, 2-11-1 Morioka-eki Nishi-dori, Morioka, Iwate, Japan. ${ }^{3}$ East Japan Railway Company, 2-2-2 Yoyogi, Shibuya-ku, Tokyo, Japan. ${ }^{4}$ Kamaishi Forest Owner's Association, 1-1-1 Katagishi-cho, Kamaishi, Iwate, Japan.

\section{Acknowledgements}

A part of this research is on the support of Iwate Next Future Industry Seeds Growing Research. We would like to thank the cooperation of Kamaishi Forest Owner's Association and Ishimura industrial Co. Ltd.

\section{Competing interests}

The authors declare that they have no competing interests.

Received: 28 October 2016 Accepted: 22 February 2017

Published online: 03 March 2017

\section{References}

1. Editorial Committee of Wood Industry Handbook (1982) Wood Industry Handbook. Maruzen, Tokyo (In Japanese)
2. Fukuoka T, Matsuo Y, Shirai Y, Yamamoto Y, Watai J, Mozuna M, Sugano S (2012) Development of cutting down manipulator system equipped with remote control for safe thinning operation: investigation of felling trees using hydraulic cylinder (robots for works), Proceedings of JSME Conference on Robotics and Mechatronics, 1P1-G04 (In Japanese)

3. Gui P, Tang L, Mukhopadhyay S (2015) A novel design of anti-falling mechanism for tree pruning robot. Proceedings of IEEE international conference on industrial electronics and applications

4. Ikeda et al (1994) Tree felling method using explosion, Japanese patent (H6-46693)

5. Ishigure Y, Hirai K, Kawasaki H (2013) A pruning robot with a powersaving chainsaw drive. Proceedings of IEEE international conference on mechatronics and automation

6. Japanese Forestry Agency. How of drew up of new forest and forestry basic plan. http://www.rinya.maff.go.jp/j/kikaku/plan/ (In Japanese)

7. Japanese Forestry Agency. White book of forest and forestry in $\mathrm{H} 21$. http://www.rinya.maff.go.jp/j/kikaku/hakusyo/21 hakusho/index.html (In Japanese)

8. Japanese Ministry of Health 1. Labour and welfare of Japan, condition of industrial injurance according to type of business. http://www.mhlw. go.jp/stf/houdou/0000046019.html (In Japanese)

9. Japanese Ministry of Health 2. Labour and welfare of Japan, move of one-thousand rate according to type of business. http://anzeninfo.mhlw. go.jp/information/h08_25_sen01.html (In Japanese)

10. Kolb A, Meaclem C, Chen X, Parker R, Gutschmidt S, Milne B (2015) Tree trunk detection system using LiDAR for a semi-autonomous tree felling robot. Proceedings of IEEE international conference on industrial electronics and applications

11. Meaclem CV, Shao L, Parker R, Gutschmidt S, Hann CE, Milne BJ, Chen XQ (2014) Sensor guided biped felling machine for steep terrain harvesting. Proceedings of IEEE international conference on automation science and engineering

12. Takeuchi M, Suga Y, Shirai Y, Sugano S (2010) Development of street tree climbing robot for pruning branches WOODY-2: implementation of and experiment on adjust function of grasping power. Proceedings of JSME conference on robotics and mechatronics. 1A1-A21 (In Japanese)

\section{Submit your manuscript to a SpringerOpen ${ }^{\circ}$ journal and benefit from:}

- Convenient online submission

- Rigorous peer review

- Immediate publication on acceptance

- Open access: articles freely available online

- High visibility within the field

- Retaining the copyright to your article

Submit your next manuscript at $>$ springeropen.com 